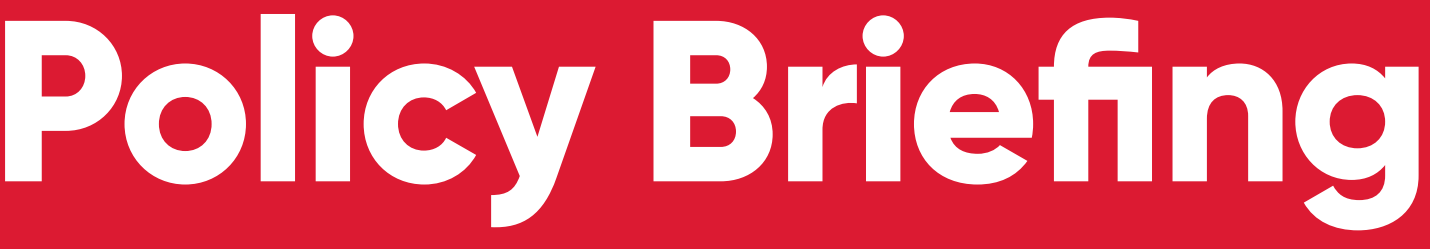

\title{
Improving Access to
}

\section{Education for Marginalised Girls in Conflict Areas}

A high proportion of out-of-school children across the world live in conflict-affected contexts. To remove barriers to education for marginalised girls in those contexts, a key challenge is to understand the multiple and intersecting forms of marginalisation and their changing dynamics during violent conflict. Research from the REALISE education project in the Democratic Republic of the Congo (DRC) identifies key considerations for education programmes for marginalised girls in conflict areas, such as inclusive education for girls and boys, links between education and peace-building, and extra-curricular activities to support social relationships.

\section{Key messages}

- Education programmes can help remove barriers for marginalised girls in violent and conflict settings. Understanding the multiple and intersecting forms of economic, social, political and gender-based marginalisation is vital to achieve this objective.

- Key ways to do this include monitoring and reviewing how conflict is changing who is marginalised, supporting boys as well as girls to prevent resentment, and helping to ensure timely payments to prevent exclusion.

- Social networks are key, and programmes should reinforce activities that strengthen social relationships and social protection.

- Education programmes can also benefit from considering the wider links between education and peace-building.

ids.ac.uk
66

The effect of
conflict on
education
varies from
group to group,
and it is crucial
to understand
these differences
when designing
education
policies.

Gauthier Marchais, Sweta Gupta and Cyril Brandt 


\section{Dimensions of marginalisation in war}

\section{'Unpacking' the dynamics of violent conflict and marginalisation}

A high proportion of out-of-school children across the world live in conflict-affected contexts. Recent literature has made substantial advances in understanding marginalisation from education in crisis, emergency, and post-conflict scenarios. Substantial evidence exists, for example, on the targeting of schools, students and teachers by armed actors, lost days of schooling due to displacement, and the use of schools for military purposes. However, there is limited understanding of access to education in contexts where violence is protracted and entrenched.

Conflict-affected areas display significant variation in terms of military, political, institutional and social configurations. Understanding how different dimensions of marginalisation manifest and operate requires attention to the specificities of each context. Our research explores first, how violent conflict can enhance or reduce preexisting forms of marginalisation and second, how new forms of marginalisation emerge as a result of violent conflict.

\section{Addressing economic marginalisation in war}

Financial constraints are a significant barrier to education in low-income countries, and they are exacerbated in contexts of violent conflict, when households face a negative income shock.

The study shows that, in periods of crisis, teachers and school staff take a range of

\section{0}

\section{Marginalisation from education is both a result and driver of the historical marginalisation of ethnocultural and identity groups.}

measures to mitigate the increase in financial constraints to schooling. These include the temporary reduction or cancellation of school fees for all students within a school, or for specific groups of students - in particular, internally displaced persons and indigenous groups. These are part of a range of bottomup initiatives taken by education actors to deal with situations of crisis.

Numerous projects, including REALISE, have also sought to reduce financial barriers to education, notably by providing bursaries to students. This is also the aim of Gratuité, the policy that the Congolese government has been rolling out since September 2019, which aims to provide free access to primary school children. To assist teachers in dealing with overcrowded classrooms due to Gratuité, REALISE introduced adapted Teacher Professional Development modules.

Our research, carried out before the Gratuité policy, shows that in contexts where schools are largely financed by household contributions, teachers without a regular government income suffer the most when households are no longer able to pay 'teacher incentives'. Schools might continue to be negatively affected by income shocks even after Gratuité as long as non-paid teachers are left off the government's payroll (a process not finalised as of June 2021). As salaries are an important motivator for teacher retention, it is likely that this drop in teacher income enhances the negative effects of conflict on teachers, further demotivating them and increasing teacher turnover. This turnover can negatively impact interventions in the field of teacher training: when schools are unable to retain trained teachers, investments in their professional development might not be sustainable. Therefore, it is important for education interventions aiming to increase school attendance to remain aware of the links between different project components, such as scholarships and teacher professional development. 
Social marginalisation, violent conflict, and enrolment

Social networks often condition access to resources and services. Particularly in conflict-affected contexts, social networks and relationships also condition exposure to various dynamics of violent conflict, from direct violence to recruitment or exploitative practices. They are therefore key in understanding dynamics of marginalisation from education. The research shows that a household's social ties with authorities and participation in village groups (such, as women's groups, religious groups, savings' groups) is positively associated with school enrolment, and the effect is stronger for poorer households. Conversely, social marginalisation can significantly increase educational marginalisation. These results suggest that programmes should bolster their social components and embed social protection in their approaches.

\section{Political marginalisation of identity groups}

The study shows that the political marginalisation of ethnocultural and other identity groups is key in understanding marginalisation from education in contexts of protracted conflict. First, marginalisation from education is both a result and driver of the historical marginalisation of ethnocultural and identity groups. As education conditions access to political and economic resources and positions, the exclusion of particular groups reinforces their political exclusion, in turn reinforcing educational marginalisation. Educational marginalisation can be central in grievances that underpin violent conflicts, which are often pitted along ethnic identity lines. Not addressing these aspects might potentially fuel the underlying drivers of violent conflict.

Second, some groups might be more severely affected by violent conflict. For example, the results show that the Twa minority of Tanganyika has not only been more exposed to violence during the

\section{Violent conflict can redraw the lines of marginalisation by reinforcing existing marginalisation, causing the marginalisation of new groups, or providing marginalised groups with new opportunities.}

Twa-Bantu conflict, but also that exposure to violence has more severe effects on the Twa than other groups in terms of educational outcomes. We analyse key mechanisms, in particular spatial segregation and the social segregation of schools along ethnic identity lines. Thus, the effect of conflict on education varies from group to group, and it is crucial to understand these differences when designing education policies.

Third, violent conflict often alters and redefines the political configuration of particular areas and the access of particular groups to resources, services and education. A group which might have had access to education could be entirely excluded from it following the political and spatial reconfiguration induced by violent conflict. Similarly, a formerly excluded group might gain more access to education due to the reconfiguration.

\section{Gender and marginalisation}

Finally, the study looks at gendered marginalisation from education, and how it interacts with the other dimensions. We find that, while there is an overall gender gap in educational outcomes, the gender gap is significantly starker for certain ethnocultural groups, particularly the Twa of Tanganyika. This result further reinforces the necessity of considering gender among other types of marginalisation. 


\section{Policy recommendations}

\section{Monitor how violent conflict alters} marginalisation. Violent conflict can redraw the lines of marginalisation by reinforcing existing marginalisation, causing the marginalisation of new groups, or providing marginalised groups with new opportunities. Awareness of this is crucial to avoid education interventions that are based on outdated patterns and dynamics.

2. Include the entire student body. Even when a project focuses on girls, providing some support to boys and girls can offset the potential for grievances to build and discrimination to occur. Learning from the previous Girls' Education Challenge project in the DRC, the REALISE project also supported boys with class kits, textbooks, and access to clubs.

\section{Ensure timely payments of school fees.} In a context where children were often expelled at the end of the month due to non-paid fees, timely payments were crucial to ensuring students' continuous attendance. Regular monitoring of the adequacy of innovative payment schemes should be carried out, especially in contexts of irregular access to phone and digital infrastructure.

\section{Consider wider education and} peace-building links. When armed conflict is rooted in the marginalisation of certain groups of people, education projects can inadvertently reinforce inequalities of access to education. It is important to carefully consider the inequalities of access to education for different groups which education programmes might themselves generate or reinforce.

\section{Reinforce activities that create social relationships and social protection.} Evidence shows that social isolation has detrimental effects on access to education for boys and girls. Programmes should encourage social relationships and networks to develop, such as Village Saving and Loans Groups or Sexual and Reproductive Health Clubs - both important REALISE interventions. Embedding social protection approaches within education policies and programmes can also be beneficial.
Institute of Development Studies, Library Road, Brighton BN1 9RE, United Kingdom +44 (0)1273 606261 ids.ac.uk IDS is a charitable company limited by guarantee and registered in England. Charity Registration Number 306371 Charitable Company Number 877338.

\section{Further reading}

Marchais, G. et al. (2021) Marginalisation from Education in Conflict-Affected Contexts: Learning from Tanganyika and Ituri in the DR Congo, IDS Working Paper 544, Brighton: Institute of Development Studies, DOI: 10.19088/IDS.2021.017

De Herdt, T.; Marivoet, W. and Muhigirwa, F. (2015) Analyse de la situation des enfants et des femmes en RDC 2015. Vers la réalisation du droit à une éducation de qualité pour tous, Kinshasa: UNICEF RDC

Gordon, R.; Marston, L.; Rose, P. and Zubairi, A. (2019) 12 Years of Quality Education for All Girls: A Commonwealth Perspective Cambridge: REAL Centre, University of Cambridge

Matabishi Namashunju, S. (2016) 'Langues, éducation et développement durable en République Démocratique du Congo', PhD thesis, University of Rouen
This IDS Policy Briefing was written by Gauthier Marchais (IDS), Sweta Gupta (IDS) and Cyril Brandt (IDS and IOB Antwerp), edited by Sophie Robinson (IDS) and supported by Deborah West (IDS). It was produced as part of the Girls' Education Challenge REALISE education project funded by the Foreign, Commonwealth \& Development Office (FCDO) as part of the Girls' Education Challenge and led by Save the Children, in partnership with World Vision International.

The opinions expressed are those of the authors and do not necessarily reflect the views or policies of IDS or the UK government.

(c) Institute of Development Studies 2021.

cc (i) This is an Open Access briefing distributed under the terms of the Creative Commons Attribution 4.0 International licence (CC BY), which permits unrestricted use, distribution, and reproduction in any medium, provided the original authors and source are credited and any modifications or adaptations are indicated. ISSN 1479-974X DOI: 10.19088/IDS.2021.053 